Copyright (C) 2021 University of Bucharest Printed in Romania. All rights reserved

ISSN print: $1224-5984$

ISSN online: $2248-3942$
Rom Biotechnol Lett. 2021; 26(3): 2664-2670 doi: $10.25083 / \mathrm{rbl} / 26.3 / 2664.2670$

Received for publication, January, 11, 2019

Accepted, July, 12, 2019

Original paper

\title{
Dental biofilm-induced gingivitis in children and adolescents. A literature review
}

\author{
ȘTEFANA POPA ${ }^{1}$, STANA PĂUNICĂ ${ }^{1}$, MARINA CRISTINA GIURGIU ${ }^{1}$, DANA \\ BODNAR ${ }^{2}$, IOANA SUCIU ${ }^{3}$, ALEXANDRA TOTAN ${ }^{4}$, ANCA SILVIA DUMITRIU ${ }^{1}$, \\ ANDREEA CRISTIANA DIDILESCU ${ }^{5 *}$
}

${ }^{1}$ Division of Periodontology, Faculty of Dental Medicine, "Carol Davila" University of Medicine and Pharmacy, Bucharest, Romania

${ }^{2}$ Division of Odontology, Faculty of Dental Medicine, "Carol Davila" University of Medicine and Pharmacy, Bucharest, Romania

${ }^{3}$ Division of Endodontics, Faculty of Dental Medicine, "Carol Davila" University of Medicine and Pharmacy, Bucharest, Romania

${ }^{4}$ Division of Biochemistry, Faculty of Dental Medicine, "Carol Davila" University of Medicine and Pharmacy, Bucharest, Romania

${ }^{5}$ Division of Embryology, Faculty of Dental Medicine, "Carol Davila" University of Medicine and Pharmacy, Bucharest, Romania

\begin{abstract}
Dental biofilm-induced gingivitis is extremely common in children and adolescents and it affects the majority of children over 7 years old. It is characterised by inflammation, consisting in changes of colour, size, consistency and texture. Although most of the times gingivitis does not progress into periodontitis, it is important to diagnose and properly treat this disease, as gingivitis precedes periodontitis. The present paper aims to review the main findings of microbial etiology and epidemiology of dental biofilm-induced gingivitis mediated by local risk factors, as well as the role of oral hygiene in preventing bacterial colonization.
\end{abstract}

Keywords Gingivitis, caries, calculus, prevention, children.

To cite this article: POPA Ș, PĂUNICĂ S, GIURGIU MC, BODNAR D, SUCIU I, TOTAN A, DUMITRIU AS, DIDILESCU AC. Dental biofilm-induced gingivitis in children and adolescents. A literature review. Rom Biotechnol Lett. 2021; 26(3): 2664-2670. DOI: $10.25083 / \mathrm{rbl} / 26.3 / 2664-2670$

*Corresponding author: ANDREEA CRISTIANA DIDILESCU, 8 Eroii Sanitari Boulevard, 050474, Bucharest, Romania, Tel.: +40722536798

E-mail: andreea.didilescu@umfcd.ro 


\section{Introduction}

Periodontal diseases were the most common disorders found at the mummies of the ancient Egypt. Ebers Papyrus (an Egyptian medical papyrus of herbal knowledge dating from around $1550 \mathrm{BC}$ ) contains numerous references about gum diseases, and offers some prescriptions for strengthening teeth and gums. The medical works of the ancient India and China dedicated an important space to the oral conditions, including periodontal problems and oral hygiene, and described the gingival inflammation, the periodontal abscess, and the gingival ulcerations (GOLD, 1985). Periodontal disease results from the complex interaction between the subgingival biofilm and the host immune inflammatory reactions that take place in the gingival and periodontal tissues as a response to the presence of the pathogens in the bacterial plaque (NEWMAN et al, 2014).

Superficial periodontal diseases, known as gingival diseases, have been recently classified into two groups, as follows (CATON et al, 2018):

\section{Gingivitis-dental biofilm-induced}

a. Associated with dental biofilm alone;

b. Mediated by systemic or local risk factors;

c. Drug-influenced gingival enlargement.
Gingival diseases - non-dental biofilm induced

a. Genetic/developmental disorders;

b. Specific infections;

c. Inflammatory and immune conditions;

d. Reactive processes;

e. Neoplasms;

f. Endocrine, nutritional \& metabolic diseases;

g. Traumatic lesions;

h. Gingival pigmentation.

Dental biofilm-induced gingivitis (DBIG) is extremely common in children and adolescents and it affects more than $70 \%$ of the children over 7 years old (CALIFANO, 2003, OH et al, 2002). It is characterised by inflammation, generally traced at the level of interdental papillae and free gingival margin, consisting in changes of colour, size, consistency and texture, in most cases with undetectable loss of bone or connective tissue attachment (Figs. 1, 2). Also, on objective clinical examination, bleeding on probing is usually not detected. Although most of the times gingivitis does not progress into periodontitis, is important to diagnose and treat this disease because periodontitis is preceded by gingivitis $(\mathrm{OH}$ et al, 2002).

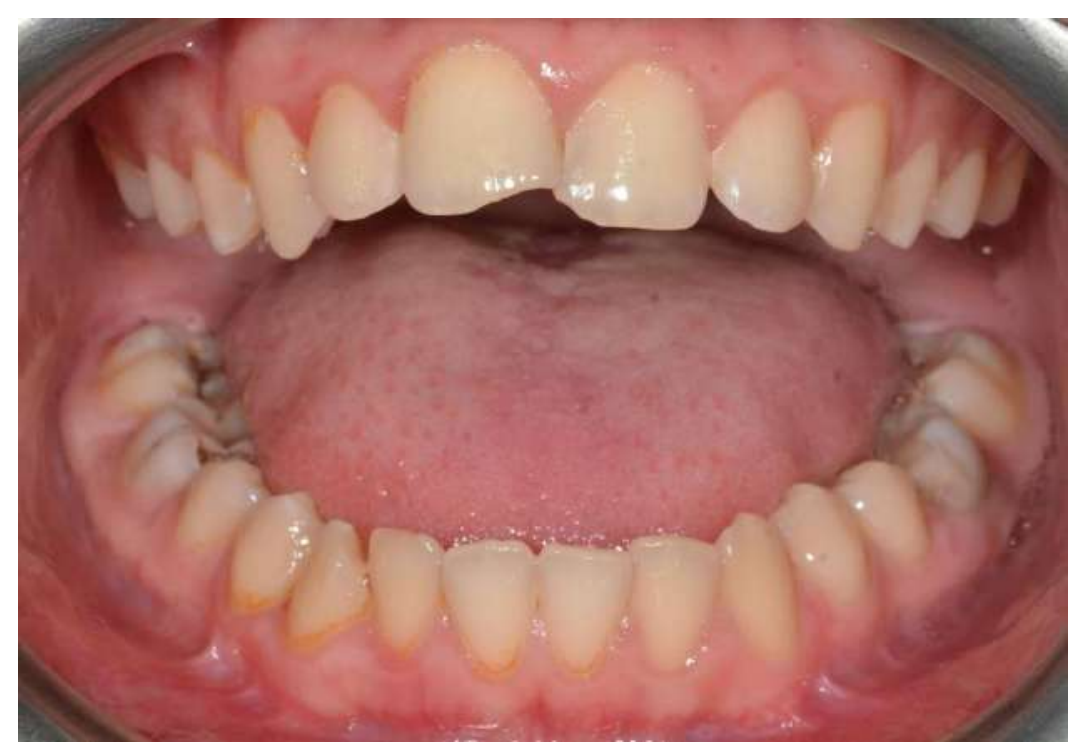

Figure 1. Inflammatory signs of the free gingival margin and interdental papilla, with the presence of carious lesions in molars and teeth colorations.

The aim of the present paper is to review the main findings of microbial etiology and epidemiology of DBIG mediated by local risk factors, as well as the role of oral hygiene in preventing bacterial colonization.

\section{The bacterial etiology of DBIG}

The bacterial plaque is considered the causing factor in gingivitis. The intensity of gingival diseases increases as the child grows due to changes of the microbial flora (BIMSTEIN and MATSSON, 1999). Yang et al (2002) analyzed bacterial plaque samples of children and reported that $71 \%$ of $18-48$ month-old children were infected with at least one periodontal pathogen. Thus, $68 \%$ were infected with Porphyromonas gingivalis, and $20 \%$ exhibited Bacteroides forsythus (YANG et al, 2002). In another study, the majority of children and adolescents 


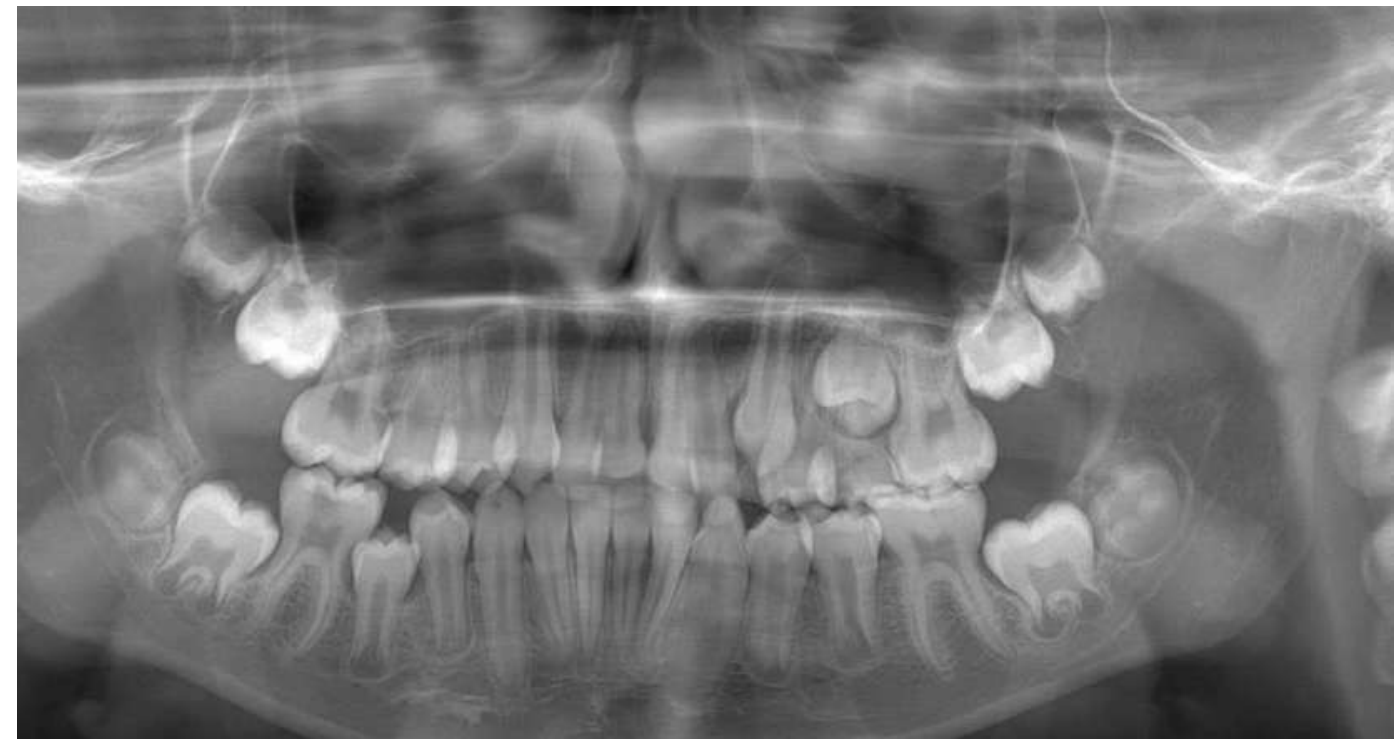

Figure 2. Panoramic X-ray: no changes detected in the deep periodontium

(60\%), between 2 and 18 years old, presented levels of $P$. gingivalis in the bacterial plaque, and $75 \%$ showed similar levels of Actinobacillus actinomycetemcomitans (MORINUSHI et al, 2000). Experimental gingivitis models in children have found increased subgingival levels of Actinomyces sp., Capnocytophaga sp., Leptotrichia sp. and Selenomonas sp. (MOORE et al, 1984), pathogens that are generally not seen in adult gingivitis, thereby raising interest in their potential role in the etiology of childhood gingivitis.

With regards to DBIG epidemiology, numerous studies have similar results, disregarding the cultural and socio-economical status of the population. A study performed on 995 children between 6 and 11, living in three different areas of the city Tafeleh Governorate (South Jordan), reported that $70.2 \%$ of the children presented signs of gingival inflammation (RODAN et al, 2015). Within the same study, according to the gingival index, $29.8 \%$ had healthy gingiva, $38.5 \%$ mild gingivitis, $31.4 \%$ moderate gingivitis, and $0.3 \%$ severe gingivitis. A recent study conveyed in Lucknow (India) on children aged 8 to 16 years, has revealed that most school children $(71.11 \%)$ between the ages of 8 to 10 suffered from gingivitis, in various forms of severity, mostly mild to moderate (SINGH, 2014). In a study in Tehran, $87.7 \%$ of the study subjects, children aged 9 to 13 years, had gingivitis (JESSRI et al, 2013). A study conducted in Lithuania showed that $59.6 \%$ of school children, aged 6 to 8 years, suffered from light gingivitis (PAURAITE et al, 2003). Another study performed on Lithuanian school children of ages between 11 and 15 years, has shown that more than $50 \%$ of them were complaining of bleeding gums (ZABORSKYTE and BENDORAITIENE, 2003). Gingival bleeding was also found in $41.5 \%$ of Greek 12 years old population (VADIAKAS et al, 2012), and in $32.8 \%$ of the children aged 6 to 12 years from the Danube Delta Biosphere Reserve (JIPA and AMARIEI, 2012).

When it comes to favouring the pathogenic action of microbes involved in gingivitis with children, an important part is played by supra- and subgingival dental calculus, and carious lesions (Fig. 3). They do not contribute in a direct manner to gingival inflammation, but offer a steady support for the continuous accumulation of plaque and keeping it in the immediate proximity of the gum.

\section{Dental calculus and gingivitis}

Dental calculus consists of mineralized bacterial plaque that forms on the surfaces of the teeth. Calculus deposits are uncommon in infants and toddlers, but can increase with age. It can be observed in children aged 4 to 6 years old in a relatively low percentage, approximately $9 \%$. Instead, $18 \%$ of the children of ages 7 to 9 years old and $33 \%$ to $43 \%$ of those with ages from 10 to 15 years old, presented plaque deposits (WOTMAN et al, 1973).

In a study performed by Krisdapong et al (2012) on children aged 12 and 15 years, it was observed that most of the children had gingivitis and/or calculus $(79.3 \%$ and $81.5 \%$, respectively).

\section{Dental caries and gingivitis}

Dental caries is an ubiquitous process defined as the result of a localized chemical dissolution of the tooth surface caused by acid production by the dental biofilm exposed frequently to sugars (FEJERSKOV and KIDD, 2009). Following this concept, it may be stated that the dental biofilm is a biological determinant associated with the development of both periodontal diseases and dental caries. (FIGUERO et al, 2017). 


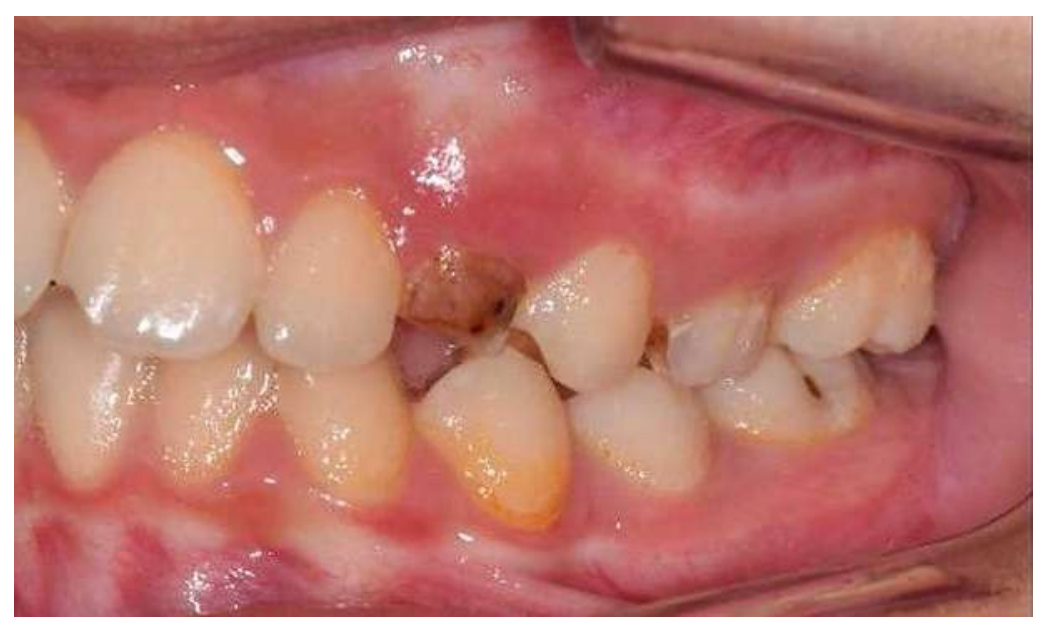

Figure 3. Inflammatory signs of the free gingival margin and interdental papilla, due to the presence of subgingival calculus $(2.1,2.2)$, bacterial plaque and carious lesions.

According to World Health Organization (WHO), carious lesions of permanent teeth are the most widely spread affections, and according to Global Burden of Disease Study (GBD) (2016), it is the second disease with high incidence. The incident rate is followed by superior respiratory infections (VOS et al, 2017). Carious lesions affect $60 \%$ to $90 \%$ of the school children and almost $100 \%$ of the adult population in many countries (PETERSEN et $\mathrm{al}, 2005)$. Moreover, most children and adolescents from underdeveloped countries present signs of gum disease (bleeding gums), (PETERSEN et al, 2005).

Although dental caries affect most people, their prevalence varies very much around the world (IRIGOYEN et al, 2012). These differences are attributable to the differences in risk factors, such as diet or fluoridated water availability (MAUPOME et al, 2013) or to the cultural and social factors, also included in the analysis of the risk factors for caries and periodontal diseases (FONTANA et al, 2011). One of these factors was analyzed in a study that aimed to compare the oral health of youth from rural and urban zones in central Chile (QUINTEROS et al, 2014). Living in a rural area led to inequities in education and health, and limited access to services. Rural areas are usually associated with low income, which also represents a major risk factor for these diseases (PETERSEN and KWAN, 2011). In central Chile, there was a significantly higher prevalence of caries in children of 12 years old from rural areas $(67.5 \%)$ than in those from urban areas (54.04\%), (GIACAMAN et al, 2018).

According to data supplied by the Health and Social Protection Ministry in Columbia in 2014, the prevalence of dental cavities was $62 \%$ in children of 5 years old, $52 \%$ in 12 years category, and $76 \%$ in adults between 30-34 years (HERRERA SERNA and LÓPEZ SOTO, 2018).

\section{Oral hygiene and preventive programmes for gingivitis}

Oral hygiene represents an important preventive factor that can be personally controlled, and can be improved through small changes of technique and habits (LEVINE, 2004, FOLAYAN et al, 2014).

\section{Mechanical plaque control}

Oral hygiene means intend to eliminate or modify the structure of the dental plaque (GAUBA et al, 2013). Therefore, dental brushing is a mechanical process that aims to dismantle the biofilm, even if it fails the complete removal, especially in young children who have not yet developed motor skills to apply a proper oral hygiene technique (SICCA et al, 2016). This destructuring prevents the plaque to have pathological effects.

School stage represents the period when most habits are acquired as permanent. Oral health education implemented in this period is important for determining healthy habits (CHUNG et al, 2006).

The preventive means aim at sensitizing managers in health care and school teachers to implement a program of daily brushing in schools, beginning with the primary school, in order to fix a behavior, to control the dental plaque, and to prevent the caries occurrence and gum inflammation in children. The main objective of the oral education is to motivate the individuals in terms of disease prevention, keeping teeth, and taking responsibility for their oral health. Children who underwent the oral health program during 72 months succeeded to considerably improve their brushing technique. Consequently, the oral hygiene has been ameliorated, leading to a better gingival health (HERRERA SERNA and LÓPEZ SOTO, 2018). Most studies, even with a shorter follow-up, showed a 
significant progress in controlling the level of the dental plaque (MARCON et al, 2016). This thing coincides with the study results of Schlueter et al (2010), which reported that repeating motivation every session, using various leaflets, instructions, and interactive demonstrations were efficient for improving the brushing technique.

Among young children, the simple method of "horizontal brushing" has been shown to be effective in controlling the dental plaque (LEVINE, 2004). MullerBolla and Courson (2013) developed a systematic analysis to evaluate children's ability to remove the dental plaque, and also to be able to identify the most efficient methods of brushing. So, for the children of 6-7 years old, they noticed that the horizontal technique was the most efficient, being easy to learn and apply, and efficient in removing the plaque (MULLER-BOLLA and COURSON, 2013). Bergstrom and Lavstedt (1979) suggested that the horizontal technique should be recommended for school-age children, and its efficiency has been demonstrated by Harnacke et al (2012).

In Scandinavian countries, a series of controlled clinical trials demonstrated the efficacy of professional tooth cleaning (PTC), including flossing and using 5\% monofluorophosphate prophylactic paste compared to toothbrushing with $0.2 \%$ sodium floride $(\mathrm{NaF})$ solution (LINDHE and AXELSSON, 1973) and to use of mouthrinse with $0.2 \% \mathrm{NaF}$ solution (HAMP et al, 1978). After finishing the study they observed significant reductions in plaque and gingival scores, concurrently with significantly lower caries increment in the test groups. Similar results were obtained in a study performed in Russia, in which no interventions were offered to control groups (EKSTRAND et al, 2000). In Denmark, significant reductions in plaque and gingival scores and low caries increment were recorded only by using the PTC and topical fluoride application at regular intervals (PETERSEN, 1989).

\section{Chemical plaque control}

It is recognized and accepted that chlorhexidine (CHX) remains the gold standard as antiplaque and antigingivitis agent (MATTHIJS and ADRIAENS, 2002). However, the anticaries effect of $\mathrm{CHX}$ is questionable.

The use of CHX in concentrations of $0.1 \%$ or $0.2 \%$ in mouthrinse in children, for 6 months, achieve significant reductions for plaque and gingival indices, and no differences for caries increment, compared with a placebo (LANG et al, 1982).

In a study performed on a sample of more than 1200 Scottish schoolchildren, the authors failed to demonstrate any reduction in caries increment over a 3-year period, when a 10\% CHX varnish was applied 6-12 times (FORGIE et al, 2000). Splieth et al (2000) selected caries-active schoolchildren who had developed more than 1 new lesion per year for the past years, for a treatment combination of $\mathrm{CHX}$ varnish and fluoride gel versus fluoride gel controls. Even if the experimental group developed less caries over 12 months, there were no significant differences. Another study was performed in Surinam with semi-annual CHX varnish applications, and again no effect on caries increment in schoolchildren was demonstrated (SOET et al, 2002).

\section{Conclusions}

The microbial etiology of gingivitis is a fact acknowledged. However, the pathogenic action of the bacteria is accomplished in children and adolescents, in the presence of carious lesions, calculus and/or poor hygiene. Therefore, there is a need to provide prophylactic treatment, as well as screening procedures within the population groups at risk, in order to establish the most appropriate curative treatment.

\section{Conflict of interest disclosure}

There are no known conflicts of interest in the publication of this article. All authors have read and approved the manuscript. All authors have equally contributed to the present work.

\section{References}

1. BERGSTROM J, LAVSTEDT S. An epidemiologic approach to toothbrushing and dental abrasion. Community Dent Oral Epidemiol, 1979; 7(1): 57-64.

2. BIMSTEIN E, MATSSON L. Growth and development considerations in the diagnosis of gingivitis and periodontitis in children. Pediatr Dent, 1999; 21(3): 186-91.

3. CALIFANO JV. Position paper: periodontal diseases of children and adolescents. J Periodontol, 2003; 74(11): 1696-704. 10.1902/jop.2003.74.11.1696

4. CATON JG, ARMITAGE G, BERGLUNDH T, CHAPPLE ILC et al. A new classification scheme for periodontal and peri-implant diseases and conditions Introduction and key changes from the 1999 classification. J Periodontol, 2018; 89 Suppl 1: S1-S8. 10.1002/JPER.18-0157

5. CHUNG MH, KASTE LM, KOERBER A, FADAVI S et al. Dental and medical students' knowledge and opinions of infant oral health. J Dent Educ, 2006; 70(5): 511-7.

6. EKSTRAND KR, KUZMINA IN, KUZMINA E, CHRISTIANSEN ME. Two and a half-year outcome of caries-preventive programs offered to groups of children in the Solntsevsky district of Moscow. Caries Res, 2000; 34(1): 8-19. 10.1159/000016564 
7. FEJERSKOV O, KIDD E, 2009. Dental caries: the disease and its clinical management, John Wiley \& Sons.

8. FIGUERO E, NOBREGA DF, GARCIA-GARGALLO M, TENUTA LM et al. Mechanical and chemical plaque control in the simultaneous management of gingivitis and caries: a systematic review. J Clin Periodontol, 2017; 44 Suppl 18: S116-s134. 10.1111/jcpe. 12674

9. FOLAYAN MO, ADENIYI AA, CHUKWUMAH NM, ONYEJAKA $\mathrm{N}$ et al. Programme guidelines for promoting good oral health for children in Nigeria: a position paper. BMC Oral Health, 2014; 14: 128. 10.1186/1472-6831-14-128

10. FONTANA M, JACKSON R, ECKERT G, SWIGONSKI $\mathrm{N}$ et al. Identification of caries risk factors in toddlers. J Dent Res, 2011; 90(2): 209-14. $10.1177 / 0022034510385458$

11. FORGIE AH, PATERSON M, PINE CM, PITTS NB et al. A Randomised Controlled Trial of the CariesPreventive Efficacy of a Chlorhexidine-Containing Varnish in High-Caries-Risk Adolescents. Caries Research, 2000; 34(5): 432-439. 10.1159/000016619

12. GAUBA A, BAL IS, JAIN A, MITTAL HC. School based oral health promotional intervention: Effect on knowledge, practices and clinical oral health related parameters. Contemp Clin Dent, 2013; 4(4): 493-9. 10.4103/0976-237X.123056

13. GIACAMAN RA, BUSTOS IP, BAZAN P, MARINO RJ. Oral health disparities among adolescents from urban and rural communities of central Chile. Rural Remote Health 2018; 18(2): 4312. 10.22605/RRH4312

14. GOLD SI. Periodontics. The past. Part (I). Early sources. J Clin Periodontol, 1985; 12(2): 79-97. 10.1111/j.1600-051x.1985.tb01367.x

15. HAMP SE, LINDHE J, FORNELL J, JOHANSSON LA et al. Effect of a field program based on systematic plaque control on caries and gingivitis in schoolchildren after 3 years. Community Dent Oral Epidemiol, 1978; 6(1): 17-23.

16. HARNACKE D, MITTER S, LEHNER M, MUNZERT $J$ et al. Improving oral hygiene skills by computer-based training: a randomized controlled comparison of the modified Bass and the Fones techniques. PLoS One, 2012; 7(5): e37072. 10.1371/ journal.pone.0037072

17. HERRERA SERNA BY, LÓPEZ SOTO OP. Evaluación a 72 meses de una estrategia de prevención en salud oral en escolares. Rev Esp Salud Pública, 2018; 92(6): e1-e9.

18. IRIGOYEN ME, MEJIA-GONZALEZ A, ZEPEDAZEPEDA MA, Betancourt-Linares A et al. Dental caries in Mexican schoolchildren: a comparison of 1988-1989 and 1998-2001 surveys. Med Oral Patol Oral Cir Bucal, 2012; 17(5): e825-32. 10.4317/ medoral.18008
19. JESSRI M, JESSRI M, RASHIDKHANI B, KIMIAGAR SM. Oral health behaviours in relation to caries and gingivitis in primary-school children in Tehran, 2008. East Mediterr Health J, 2013; 19(6): 527-34.

20. JIPA IT, AMARIEI CI. Oral health status of children aged 6-12 years from the Danube Delta Biosphere Reserve. Oral Health Dent Manag, 2012; 11(1): 39-45.

21. KRISDAPONG S, PRASERTSOM P, RATTANARANGSIMA K, SHEIHAM A et al. The impacts of gingivitis and calculus on Thai children's quality of life. Journal of Clinical Periodontology, 2012; 39(9): 834-843. 10.1111/j.1600-051X.2012.01907.x

22. LANG NP, HOTZ P, GRAF H, GEERING AH et al. Effects of supervised chlorhexidine mouthrinses in children. A longitudinal clinical trial. J Periodontal Res, 1982; 17(1): 101-11. 10.1111/j.1600-0765.1982. tb01135.x

23. LEVINE R. The scientific basis of oral health education. Community Dent Health, 2004; 21(2): 131-3.

24. LINDHE J, AXELSSON P. The effect of controlled oral hygiene and topical fluoride application on caries and gingivitis in Swedish schoolchildren. Community Dent Oral Epidemiol, 1973; 1(1): 9-16.

25. MARCON M, SARTI A, TUBARO S. Toothbrush motion analysis to help children learn proper tooth brushing. Comput. Vis. Image Underst., 2016; 148(C): 34-45. 10.1016/j.cviu.2016.03.009

26. MATTHIJS S, ADRIAENS PA. Chlorhexidine varnishes: a review. J Clin Periodontol, 2002; 29(1): 1-8. 10.1034/j.1600-051x.2002.290101.x

27. MAUPOME G, MARTINEZ-MIER EA, HOLT A, MEDINA-SOLIS CE et al. The association between geographical factors and dental caries in a rural area in Mexico. Cad Saude Publica, 2013; 29(7): 1407-14. 10.1590/s0102-311x2013000700014

28. MOORE WE, HOLDEMAN LV, SMIBERT RM, CATO EP et al. Bacteriology of experimental gingivitis in children. Infect Immun, 1984; 46(1): 1-6.

29. MORINUSHI T, LOPATIN D, VAN POPERIN N, UEDA Y. The Relationship Between Gingivitis and Colonization by Porphyromonas gingivalis and Actinobacillus actinomycetemcomitans in Children. Journal of periodontology, 2000; 71: 403-9. 10.1902/jop.2000. 71.3.403

30. MULLER-BOLLA M, COURSON F. Toothbrushing methods to use in children: a systematic review. Oral Health Prev Dent, 2013; 11(4): 341-7. 10.3290/j.ohpd. a30602

31. NEWMAN MG, TAKEI HH, KLOKKEVOLD PR, CARRANZA FA, 2014. Carranza's Clinical Periodontology, Elsevier Saunders.

32. OH TJ, EBER R, WANG HL. Periodontal diseases in the child and adolescent. J Clin Periodontol, 2002; 29(5): 400-10. 10.1034/j.1600-051x.2002.290504.x 
33. PAURAITE J, MILCIUVIENE S, SAKALAUSKIENE J. The prevalence of gingivitis among 4-16 year old schoolchildren in Kaunas. Stomatol Baltic Dent Maxillofac J, 2003; 5: 97-100.

34. PETERSEN PE. Evaluation of a dental preventive program for Danish chocolate workers. Community Dent Oral Epidemiol, 1989; 17(2): 53-9.

35. PETERSEN PE, BOURGEOIS D, OGAWA H, ESTUPINAN-DAY $S$ et al. The global burden of oral diseases and risks to oral health. Bull World Health Organ, 2005; 83(9): 661-9. /s0042-9686200 5000900011

36. PETERSEN PE, KWAN S. Equity, social determinants and public health programmes - the case of oral health. Community Dent Oral Epidemiol, 2011; 39(6): 481-7. 10.1111/j.1600-0528.2011.00623.x

37. QUINTEROS ME, CACERES DD, SOTO A, MARINO RJ et al. Caries experience and use of dental services in rural and urban adults and older adults from central Chile. Int Dent J, 2014; 64(5): 2608. 10.1111/idj.12118

38. RODAN R, KHLAIFAT F, SMADI L, AZAB R et al. Prevalence and severity of gingivitis in school students aged 6-11 years in Tafelah Governorate, South Jordan: results of the survey executed by National Woman's Health Care Center. BMC Res Notes, 2015; 8: 662. 10.1186/s13104-015-1532-y

39. SCHLUETER N, KLIMEK J, SALESCHKE G, GANSS C. Adoption of a toothbrushing technique: a controlled, randomised clinical trial. Clin Oral Investig, 2010; 14(1): 99-106. 10.1007/s00784-0090269-1

40. SICCA C, BOBBIO E, QUARTUCCIO N, NICOLO $\mathrm{G}$ et al. Prevention of dental caries: A review of effective treatments. J Clin Exp Dent, 2016; 8(5): e604e610. 10.4317/jced.52890

41. SINGH A. Prevalence of gingivitis and periodontitis among schools children in Lucknow region of Uttar
Pradesh, India. IOSR Journal of Dental and Medical Sciences, 2014; 13: 21-23. 10.9790/0853-13752123

42. SOET J, GRUYTHUYSEN RJM, BOSCH J, van AMERONGEN WE. The Effect of 6-Monthly Application of $40 \%$ Chlorhexidine Varnish on the Microflora and Dental Caries Incidence in a Population of Children in Surinam. Caries research, 2002; 36: 449-55. 10.1159/000066536

43. SPLIETH C, STEFFEN H, ROSIN M, WELK A. Caries prevention with chlorhexidine-thymol varnish in high risk schoolchildren. Community Dent Oral Epidemiol, 2000; 28(6): 419-23.

44. VADIAKAS G, OULIS CJ, TSINIDOU K, MAMAIHOMATA E et al. Oral hygiene and periodontal status of 12 and 15-year-old Greek adolescents. A national pathfinder survey. Eur Arch Paediatr Dent, 2012; 13(1): 11-20.

45. VOS T, ABAJOBIR AA, ABBAFATI C, ABBAS $\mathrm{KM}$ et al. Global, regional, and national incidence, prevalence, and years lived with disability for 328 diseases and injuries for 195 countries, 1990-2016: a systematic analysis for the Global Burden of Disease Study 2016. 2017.

46. WOTMAN S, MERCADANTE J, MANDEL ID, GOLDMAN RS et al. The occurrence of calculus in normal children, children with cystic fibrosis, and children with asthma. J Periodontol, 1973; 44(5): 27880. 10.1902/jop.1973.44.5.278

47. YANG EY, TANNER AC, MILGROM P, MOKEEM SA et al. Periodontal pathogen detection in gingiva/ tooth and tongue flora samples from 18- to 48-monthold children and periodontal status of their mothers. Oral Microbiol Immunol, 2002; 17(1): 55-9.

48. ZABORSKYTE A, BENDORAITIENE E. Oral hygiene habits and complaints of gum bleeding among schoolchildren in Lithuania. Stomatologija, 2003; 5(1): 31-36. 